\title{
Exogenous 3,3'-Diindolylmethane Improves Vanadium Stress Tolerance in Brassica napus Seedling Shoots by Modulating Antioxidant Enzyme Activities
}

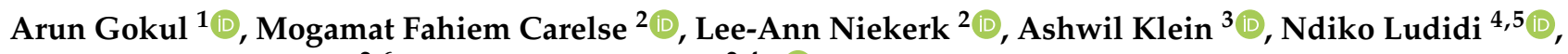 \\ David Mendoza-Cozatl ${ }^{2,6}$ and Marshall Keyster ${ }^{2,4, *}$ (D) \\ 1 Department of Plant Sciences, Qwaqwa Campus, University of the Free State, \\ Phuthadithjaba 9866, South Africa; GokulA@ufs.ac.za \\ 2 Environmental Biotechnology Laboratory, Department of Biotechnology, University of the Western Cape, \\ Bellville 7535, South Africa; 3341863@myuwc.ac.za (M.F.C.); 3255882@myuwc.ac.za (L.-A.N.); \\ MendozaCozatlD@missouri.edu (D.M.-C.) \\ 3 Plant Omics Laboratory, Department of Biotechnology, University of the Western Cape, \\ Bellville 7535, South Africa; aklein@uwc.ac.za \\ 4 DST-NRF Centre of Excellence in Food Security, University of the Western Cape, Bellville 7530, South Africa; \\ nludidi@uwc.ac.za \\ 5 Plant Biotechnology Research Group, Department of Biotechnology, University of the Western Cape, \\ Bellville 7535, South Africa \\ 6 C.S. Bond Life Sciences Center, Division of Plant Sciences, University of Missouri, Columbia, MO 65211, USA \\ * Correspondence: mkeyster@uwc.ac.za; Tel.: +27-21-959-2214
}

check for
updates

Citation: Gokul, A.; Fahiem Carelse, M.; Niekerk, L.-A.; Klein, A.; Ludidi, N.; Mendoza-Cozatl, D.; Keyster, M. Exogenous 3,3'-Diindolylmethane Improves Vanadium Stress Tolerance in Brassica napus Seedling Shoots by Modulating Antioxidant Enzyme Activities. Biomolecules 2021, 11, 436. https://doi.org/10.3390/biom11030436

Academic Editor: Mohamed A. El-Esawi

Received: 6 January 2021

Accepted: 25 February 2021

Published: 16 March 2021

Publisher's Note: MDPI stays neutral with regard to jurisdictional claims in published maps and institutional affiliations.

Copyright: () 2021 by the authors. Licensee MDPI, Basel, Switzerland. This article is an open access article distributed under the terms and conditions of the Creative Commons Attribution (CC BY) license (https:// creativecommons.org/licenses/by/ $4.0 /)$.
Abstract: 3,3'-diindolylmethane (DIM) belongs to a family of indole glucosinolate compounds that have been shown to improve Brassica napus growth through the modulation of reactive oxygen species when applied exogenously. The B. napus cultivar AV Garnet was previously identified as a vanadium-sensitive cultivar. Therefore, in this study we investigated whether exogenous DIM could improve the vanadium tolerance of AV Garnet. We performed the following experiments: seed germination assessment, dry weight assessment, cell viability assay, chlorophyll content assay, malondialdehyde (MDA) assay, conjugated diene (CD) content assay, hydrogen peroxide $\left(\mathrm{H}_{2} \mathrm{O}_{2}\right)$ content assay, superoxide $\left(\mathrm{O}_{2}{ }^{-}\right)$content determination, methylglyoxal (MG) content determination, hydroxyl radical $(\cdot \mathrm{OH})$ concentration determination, ascorbate peroxidase (APX) activity assay, superoxide dismutase (SOD) activity assay, glyoxalase I (Gly I) activity assay, glutathione S-transferase (GST) activity assay and inductively coupled plasma optical emission spectroscopy (ICP-OES) analysis for vanadium content determination. Under vanadium stress, exogenous DIM increased the seed germination percentage, shoot dry weight, cell viability and chlorophyll content. Exogenous DIM also led to a decrease in MDA, $\mathrm{CD}, \mathrm{H}_{2} \mathrm{O}_{2}, \mathrm{O}_{2}{ }^{-}, \mathrm{MG}$ and $\cdot \mathrm{OH}$, under vanadium stress in the shoots. Furthermore, DIM application led to an increase in the enzymatic activities of APX, SOD, Gly I and GST under vanadium stress. Interestingly, under vanadium stress, DIM treatment did not alter vanadium content in B. napus shoots. Our results indicate that exogenous application of DIM can improve $B$. napus seedling shoot growth and biomass under vanadium stress by priming the antioxidant enzymes via reactive oxygen species (ROS) signaling.

Keywords: 3,3'-diindolylmethane; antioxidant enzymes; Brassica napus; reactive oxygen species; vanadium

\section{Introduction}

Brassica napus is a plant species from the family Brassicaceae and is thought to have originated from the hybridization of two species, Brassica rapa and Brassica oleracea, between 6800 and 12,500 years ago. B. napus is an oil crop ranked behind soybean as the 2nd largest for oil production [1]. B. napus is widely used as a healthy source of vitamin E, for the 
production of margarine, dairy blends, animal feed, emulsifiers and cooking oils [2]. Due to its nutritional benefits in human consumption as well as animal feed, the demand for $B$. napus has rapidly increased over time [3]. However, B. napus yield is limited by heavy metal stress such as cadmium [4], lead [5], arsenic [6], chromium [7], mercury [8], nickel [9], copper [10] and vanadium stress [11].

Vanadium is ranked as the 5th most abundant transition metal and is 22nd among all discovered elements found in the Earth's crust [12]. Vanadium mining occurs extensively in Australia, South Africa, China, Russia and the United States of America. Due to extensive mining, vanadium can leach into the surrounding soils and the continuous build-up can cause pollution [13]. Therefore, Vanadium is recognized as a potentially dangerous environmental pollutant in the same class as mercury, lead and arsenic [14]. Vanadium content in the Earth's crust varies from 10 to $200 \mu \mathrm{g} \cdot \mathrm{g}^{-1}$ [15] and at testing sites vanadium mostly exist as vanadium pentaoxide $\left(\mathrm{V}_{2} \mathrm{O}_{5}\right)$, ammonium metavanadate $\left(\mathrm{NH}_{4} \mathrm{VO}_{3}\right)$, sodium metavanadate $\left(\mathrm{NaVO}_{3}\right)$ and sodium orthovanadate $\left(\mathrm{Na}_{3} \mathrm{VO}_{4}\right)$ [11]. Therefore, vanadium from the soil can get into direct contact with plants and studies have shown that elevated concentrations of vanadium reduce the root and shoot growth in Cicer arietinum [16], Glycine max [17], Citrullus lanatus [18] and Phaseolus vulgaris [19]. In most cases, plants treated with excessive vanadium display chlorosis due to chlorophyll degradation [20] as well as protein degradation [21]. In addition, vanadium toxicity leads to overproduction of reactive oxygen species (ROS) $\left(\mathrm{O}_{2}{ }^{-}, \mathrm{H}_{2} \mathrm{O}_{2}\right.$ and $\left.\cdot \mathrm{OH}\right)$, which ultimately leads to lipid peroxidation and eventually cellular death [13]. MDA and CD are oxidized by-products of membrane lipids and are considered to be bona fide indicators of lipid peroxidation in plants [22]. Heavy metals lead to the overproduction of MG, which is a reactive $\alpha, \beta$-dicarbonyl ketoaldehyde [23]. MG at cytotoxic levels can inhibit cell proliferation, as well as causing an increased degradation of proteins through the formation of advanced glycation end products [24]. However, the production of MG under vanadium stress has not been investigated to date. To combat downstream toxicity and cellular death from reactive molecules $\left(\mathrm{O}_{2}{ }^{-}, \mathrm{H}_{2} \mathrm{O}_{2}, \cdot \mathrm{OH}\right.$ and $\left.\mathrm{MG}\right)$, plants have developed enzymatic defense systems such as SOD, APX, GST and Gly I, which regulate (inactivate or detoxify) the reactive molecules under heavy metal stress.

The use of biomolecules to prime plant defense systems under heavy metal stresses have become an attractive strategy to prevent heavy metal-induced damage [25]. For instance, Nawaz et al. [18] used exogenous melatonin to reduce vanadium toxicity in C. lanatus seedlings. Parveen et al. [22] used exogenous citric acid to reduced copper stress toxicity in Corchorus capsularis seedlings. Bless et al. [26] used exogenous MG to alleviate zirconium toxicity in B. rapa seedlings. Fu et al. [27] used exogenous hydrogen sulfide to alleviate cadmium toxicity in Hordeum vulgare. Mahmud et al. [28] used $\gamma$-aminobutyric acid (GABA) to confer chromium stress tolerance on Brassica juncea. Exogenous proline and glycinebetaine were used to confer tolerance to cadmium stress on Nicotiana tabacum [29] and Vigna radiata [30]. Exogenous 5-aminolevolinic acid confers cadmium tolerance in B. napus [31]. Song et al. [32] used exogenous oxalic acid to improve the lead tolerance of Larix olgensis seedlings.

Glucosinolates are nitrogen- and sulfur-containing biomolecules, mainly found in the Brassicaceae family, with plant signaling roles under stress [33]. Glucosinolates are stable compounds under normal conditions, but they are hydrolyzed into several downstream degradation products by the enzyme myrosinase when plant tissues and cells are damaged [34]. DIM is one of the more stable by-products of indole glucosinolate breakdown and possesses signaling roles in B. napus [34] and Oryza sativa [35]. However, there are no studies that elucidate a role for DIM in heavy metal stress in plants and particularly B. napus. Therefore, we conducted this study to assess the effect of exogenous DIM pretreatment on B. napus seedlings under vanadium stress in order to elucidate potential vanadium alleviation mechanisms in plants. Our results show that DIM does protect $B$. napus against vanadium stress and our data further show that a priming of the antioxidant capacity of 
B. napus may be part of the mechanism behind the DIM-mediated alleviation mechanism against vanadium.

\section{Materials and Methods}

\subsection{Preparation of DIM}

The DIM (Sigma, St. Louis, MO, USA; $\geq 98 \%$ (HPLC); CAS Number 1968-05-4) stock solution was prepared as described by Gokul et al. [34].

\subsection{Plant Growth, Treatments and Determination of Growth Parameters}

Plant growth experiments were performed as per the method of Gokul et al. [34] with slight modifications. Planting (1200 seeds) was done in plastic pots (15 cm diameter), containing a nutrient rich potting mix (Stodels Nurseries, Cape Town, South Africa; 1 part Double Grow weed-free compost and 1 part Double Grow potting soil) under a $22{ }^{\circ} \mathrm{C} / 16^{\circ} \mathrm{C}$ day/night temperature cycle with a 16/8 h light/dark cycle, at a photosynthetic photon flux density of $300 \mu \mathrm{mol}$ photons. $\mathrm{m}^{-2} \cdot \mathrm{s}^{-1}$ (during the day phase), in a randomized design. The germination percentage of the B. napus seeds (Agricol, Cape Town, South Africa; AV Garnet cultivar) was determined by first pre-treating $(100 \mathrm{~mL})$ the pots (no seeds) with control (distilled water), $15 \mu \mathrm{M}$ DIM, $350 \mu \mathrm{M}$ vanadium $\left(\mathrm{NaVO}_{3}\right)$, and $15 \mu \mathrm{M} \mathrm{DIM}+$ $350 \mu \mathrm{M}$ vanadium for $24 \mathrm{~h}$, followed by planting all the seeds (400 seeds per treatment) and observing the number of seeds germinating (defined as seeds with radicals $3 \mathrm{~mm}$ or more in length), up until no further seeds germinated. During this time, the seedlings were treated with $100 \mathrm{~mL}$ of control, DIM, vanadium, and DIM + vanadium. Treatments were applied twice a week for 14 days and all treatments contained $0.009 \%(v / v)$ of Tween ${ }^{\circledR}-80$.

\subsection{Biomass (Dry Weight) Assessment}

At the end of the seedling stage (14 days), we removed the seedling roots to prevent erroneous data interpretation caused by possible root damage from seedling removal from the soil. Dry weight analysis was performed by drying seedling shoots (individually) per treatment at $55^{\circ} \mathrm{C}$ for $48 \mathrm{~h}$ and the weights were subsequently recorded as described by Gokul et al. [34].

\subsection{Cell Viability Assay Using Evans Blue Dye}

Cell viability was assessed using the method of Gokul et al. [34]. Briefly, the intact seedling shoot was immersed in $0.25 \%(w / v)$ Evans blue (dye content $\geq 75 \%$ ) and the dye uptake was measured by means of spectrophotometry at $600 \mathrm{~nm}$ using a FLUOstar Omega UV-visible spectrophotometer (BMG LabTech GmbH, Ortenberg, Germany).

\subsection{Chlorophyll Content Estimation}

Total chlorophyll content in the B. napus shoots was estimated using a method previously described by Nxele et al. [36]. Briefly, the weight of freshly harvested seedling shoots was recorded before homogenizing the shoots in $5 \mathrm{~mL}$ of dimethylsulfoxide (DMSO) and incubated at $65{ }^{\circ} \mathrm{C}$ for $3 \mathrm{~h}$. The absorbance rates of the extract $(200 \mu \mathrm{L})$ were recorded in a FLUOstar Omega UV-visible spectrophotometer (BMG LabTech GmbH, Ortenberg, Germany) at $645 \mathrm{~nm}$ and $663 \mathrm{~nm}$, with DMSO used as a blank.

\subsection{Determination of Lipid Peroxidation}

Lipid peroxidation was assayed by monitoring MDA production in seedling shoots and quantified using the thiobarbituric acid reactive substances (TBARS) assay as described by Zhang et al. [37]. Briefly, shoot material $(100 \mathrm{mg})$ was ground into a fine powder using liquid nitrogen. Then, the powder was homogenized in $1 \mathrm{~mL}$ of cold $6 \%(w / v)$ trichloroacetic acid (TCA). The supernatant $(100 \mu \mathrm{L})$ was mixed with $400 \mu \mathrm{L}$ of $0.5 \%$ thiobarbituric acid (TBA; prepared in $20 \%$ TCA). The resulting mixture was incubated at $95{ }^{\circ} \mathrm{C}$ for $30 \mathrm{~min}$ and the reaction was terminated on ice for $5 \mathrm{~min}$. The mixture was centrifuged at $12,000 \times \mathrm{g}$ for $5 \mathrm{~min}$ at $4^{\circ} \mathrm{C}$ and the absorbance was recorded at $532 \mathrm{~nm}$ and $600 \mathrm{~nm}$ 
using a FLUOstar Omega UV-visible spectrophotometer (BMG LabTech GmbH, Ortenberg, Germany). The non-specific absorbance was subtracted and the MDA concentration was calculated using the extinction coefficient of $155 \mathrm{mM} \cdot \mathrm{cm}^{-1}$.

\subsection{Conjugated Diene (CD) Content Assay}

A modified method by Chérif et al. [38] was followed for the CD assay. Seedling shoots from all treatments were harvested and ground into fine powders using liquid nitrogen. Then, $100 \mathrm{mg}$ of fine powder was further ground in reagent $1(3 \mathrm{~mL} \mathrm{of} 99.9 \%(v / v)$ methanol containing $100 \mathrm{mM}$ ethylenediaminetetraacetic acid (EDTA), $3 \mathrm{~mL}$ of 99.9\% (v/v) chloroform (containing amylenes as stabilizers)), and reagent 2 (3 mL of a solution containing $5 \mathrm{mM}$ EDTA and $1 \%(w / v)$ sodium chloride $(\mathrm{NaCl}))$. The mixture was centrifuged at $4000 \times g$ for $10 \mathrm{~min}\left(4^{\circ} \mathrm{C}\right)$ in glass tubes. Nitrogen gas was used to remove the chloroformic phase and the leftover residue was dissolved in $500 \mu \mathrm{L}$ of chloroform. Nitrogen gas was used to further dry $50 \mu \mathrm{L}$ of residue sample and the sample was dissolved in $800 \mu \mathrm{L}$ of absolute ethanol. A fraction of the resulting supernatant $(200 \mu \mathrm{L})$ was spectrophotometrically read at $234 \mathrm{~nm}$ with a FLUOstar Omega UV-visible spectrophotometer (BMG LabTech $\mathrm{GmbH}$, Ortenberg, Germany) and the extinction coefficient of $26.5 \mathrm{mM} \cdot \mathrm{cm}^{-1}$ was used to calculate the CD concentration.

\subsection{Hydrogen Peroxide Content Determination}

Hydrogen peroxide content was quantified using a $\mathrm{H}_{2} \mathrm{O}_{2}$ standard curve as described by Velikova et al. [39]. Briefly, shoot material $(100 \mathrm{mg})$ was ground into a fine powder in liquid nitrogen. The powder was homogenized in $1 \mathrm{~mL}$ of cold $6 \%(w / v)$ TCA and the extracts were centrifuged at $12,000 \times g$ for $30 \mathrm{~min}$ at $4{ }^{\circ} \mathrm{C}$. The supernatant $(50 \mu \mathrm{L})$ was mixed with $5 \mathrm{mM}$ dipotassium phosphate $\left(\mathrm{K}_{2} \mathrm{HPO}_{4}\right)$ at $\mathrm{pH} 5.0$ and $0.5 \mathrm{M}$ potassium iodide $(\mathrm{KI})$ in a total volume of $200 \mu \mathrm{L}$. The reaction mixture was incubated at $25^{\circ} \mathrm{C}$ for $20 \mathrm{~min}$ and the absorbance readings were recorded at $390 \mathrm{~nm}$ using a FLUOstar Omega UV-visible spectrophotometer (BMG LabTech GmbH, Ortenberg, Germany).

\subsection{Superoxide Content Determination}

Superoxide content was quantified using the method of Gokul et al. [34]. Briefly, intact seedling shoots were submerged in a solution containing $10 \mathrm{mM}$ potassium cyanide (KCN), $10 \mathrm{mM} \mathrm{H}_{2} \mathrm{O}_{2}, 2 \%(w / v)$ sodium dodecyl sulfate (SDS), $80 \mathrm{mM}$ nitroblue tetrazolium (NBT) and $50 \mathrm{mM}$ potassium phosphate buffer ( $\mathrm{pH} 7.0)$ and incubated for $20 \mathrm{~min}$. After incubation, the shoots were homogenized and centrifuged at $10,000 \times g$ for $5 \mathrm{~min}$. The supernatant was spectrophotometrically analyzed at $600 \mathrm{~nm}$ using a FLUOstar Omega UVvisible spectrophotometer (BMG LabTech $\mathrm{GmbH}$, Ortenberg, Germany). The superoxide concentration was calculated using the NBT extinction coefficient of $12.8 \mathrm{mM} \cdot \mathrm{cm}^{-1}$.

\subsection{MG Content Determination}

The MG content was calculated from a MG standard curve using a modified method, as described by Mostofa et al. [40]. Seedling shoots (200 mg) were homogenized in $2.5 \mathrm{~mL}$ $0.5 \mathrm{M}$ Perchloric acid, followed by incubation on ice for $15 \mathrm{~min}$. The extract was centrifuged for $10 \mathrm{~min}$ at $11,000 \times g$ at $4{ }^{\circ} \mathrm{C}$ and the supernatant $(1 \mathrm{~mL})$ was mixed with activated charcoal $\left(10 \mathrm{mg} \cdot \mathrm{mL}^{-1}\right)$ and kept at room temperature for $15 \mathrm{~min}$. The homogenate was centrifuged for at $11,000 \times g$ for $10 \mathrm{~min}$ and the supernatant was neutralized using saturated potassium hydroxide $(\mathrm{KOH})$ at room temperature for $15 \mathrm{~min}$. The mixture was centrifuged at $11,000 \times g$ for $10 \mathrm{~min}$. The neutralized supernatant $(650 \mu \mathrm{L})$ was mixed with $330 \mu \mathrm{L}$ of $100 \mathrm{mM}$ Phosphate buffer ( $\mathrm{pH} 7.0$ ) and $20 \mu \mathrm{L}$ of freshly prepared $0.5 \mathrm{M} \mathrm{N}$-acetyl-L-cysteine and incubated for $15 \mathrm{~min}$ at room temperature. The absorbance of the resulting supernatant was recorded at $288 \mathrm{~nm}$ with a FLUOstar Omega UV-visible spectrophotometer (BMG LabTech GmbH, Ortenberg, Germany). 


\subsection{Hydroxyl Radical Concentration Determination}

The method of Halliwell et al. [41] was used to determine $\cdot \mathrm{OH}$ concentrations in seedling shoots, with slight modifications. Intact seedling shoots were weighed and submerged in a solution containing $10 \mathrm{mM}$ phosphate buffer (pH 7.4) containing $15 \mathrm{mM}$ 2-Deoxy-D-Ribose. The samples were then incubated at $37^{\circ} \mathrm{C}$ for $4 \mathrm{~h}$. After incubation, shoots were homogenized and a volume of $0.7 \mathrm{~mL}$ of the homogenate was added to a reaction mixture containing $3 \mathrm{~mL}$ of $0.5 \%(w / v)$ TBA (made up in $5 \mathrm{mM}$ sodium hydroxide $(2 \mathrm{~mL})$ and $1 \mathrm{~mL}$ of $100 \%(v / v)$ glacial acetic acid). The sample was briefly mixed by vortex and the reaction mixture was heated for $30 \mathrm{~min}$ at $100{ }^{\circ} \mathrm{C}$. After the heating step, the sample was cooled on ice for $10 \mathrm{~min}$. The samples were centrifuged for $5 \mathrm{~min}$ at $10,000 \times g$, the resulting supernatant was spectrophotometrically monitored at 532 and $600 \mathrm{~nm}$ with a FLUOstar Omega UV-visible spectrophotometer (BMG LabTech GmbH, Ortenberg, Germany) and the $\cdot \mathrm{OH}$ concentration was determined using the extinction coefficient of $155 \mathrm{mM} \cdot \mathrm{cm}^{-1}$.

\subsection{Protein Extraction for Spectrophotometric Assays}

Seedling shoots from all treatments were harvested and ground into a fine powder using liquid nitrogen. Shoots $(200 \mathrm{mg}$ ) were homogenized in $1 \mathrm{~mL}$ of polyvinylpyrrolidone (PVP) buffer (40 mM phosphate buffer (pH 7.4), $1 \mathrm{mM}$ EDTA, 5\% $(\mathrm{m} / v)$ PVP (MW = 40,000), $5 \%(v / v)$ glycerol in distilled $\left.\mathrm{H}_{2} \mathrm{O}\right)$ and protein concentrations were determined using the RC DC Protein Assay Kit 11 (Bio-Rad Laboratories, Hercules, CA, USA), as described by Nkomo et al. [42].

\subsection{Ascorbate Peroxidase (APX) Activity Assay}

Seedling shoot APX activities were measured in extracts using a method previously described in [43]. Briefly, the protein extracts $(20 \mu \mathrm{L})$ were supplemented with $2 \mathrm{mM}$ L-ascorbic acid and incubated for $5 \mathrm{~min}$ on ice. A reaction mixture of protein extract, $50 \mathrm{mM}$ phosphate buffer (pH 7.0), $0.1 \mathrm{mM}$ EDTA and $50 \mathrm{mM}$ L-ascorbic acid was prepared. The final reaction was initiated by adding $1.2 \mathrm{mM} \mathrm{H}_{2} \mathrm{O}_{2}$ to the reaction mixture (total volume of $200 \mu \mathrm{L}$ ) and the APX activity was monitored at $290 \mathrm{~nm}$ using a FLUOstar Omega UV-visible spectrophotometer (BMG LabTech GmbH, Ortenberg, Germany) and calculated using the extinction coefficient of $2.8 \mathrm{mM} \cdot \mathrm{cm}^{-1}$.

\subsection{Total Superoxide Dismutase (SOD) Activity Assay}

Seedling shoot SOD activities were measured using a method previously described in [44]. Briefly, the protein extract $(10 \mu \mathrm{L})$ was mixed with $190 \mu \mathrm{L}$ of the assay buffer (50 mM phosphate buffer ( $\mathrm{pH} 7.8$ ), $0.1 \mathrm{mM}$ EDTA, $10 \mathrm{mM}$ methionine, $5 \mu \mathrm{M}$ riboflavin, $0.1 \mathrm{mM}$ NBT) and the mixture was incubated at room temperature for $20 \mathrm{~min}$ under fluorescent light. The absorbance was recorded at $560 \mathrm{~nm}$ using a FLUOstar Omega UVvisible spectrophotometer (BMG LabTech GmbH, Ortenberg, Germany) and SOD activity was calculated based on the amount of enzyme required to cause a 50\% reduction of NBT.

\subsection{Gly I Activity Assay}

The Gly I activity assay was performed according to the method of [45]. Briefly, a $180 \mu \mathrm{L}$ reaction assay mixture (100 mM phosphate buffer (pH 7.5), $3.5 \mathrm{mM} \mathrm{MG}, 15 \mathrm{mM}$ magnesium sulphate $\left(\mathrm{MgSO}_{4}\right)$ and $1.7 \mathrm{mM}$ glutathione (GSH)) was prepared and incubated for $10 \mathrm{~min}$ at room temperature. After incubation the reaction was initiated by the addition of the protein extract $(20 \mu \mathrm{L})$ and Gly I activity was monitored spectrophotometrically at $240 \mathrm{~nm}$ using a FLUOstar Omega UV-visible spectrophotometer (BMG LabTech GmbH, Ortenberg, Germany).

\subsection{Glutathione S-Transferase (GST) Activity Assay}

The GST activity was measured using 1-chloro-2,4-dinitrobenzene (CDNB), as per the method of [46]. Briefly, the protein extract was mixed with $100 \mathrm{mM}$ potassium phosphate 
buffer (pH 6.5), $1 \mathrm{mM}$ GSH and 1\% (v/v) absolute ethanol in a total volume of $200 \mu \mathrm{L}$. The reaction was initiated by the addition of $1 \mathrm{mM} \mathrm{CDNB}$ and kinetically followed by the use of a FLUOstar Omega UV-visible spectrophotometer (BMG LabTech GmbH, Ortenberg, Germany) at $340 \mathrm{~nm}$. The GST activity was determined using the extinction coefficient of $9.6 \mathrm{mM} \cdot \mathrm{cm}^{-1}$ for CDNB.

\subsection{Inductively Coupled Plasma Optical Emission Spectroscopy (ICP-OES) Analysis}

Sample digestion of stored shoot material of treated B. napus plants was performed according to [47]. The vanadium concentration was determined by using a Varian Vista Pro CCD simultaneous inductively coupled plasma optical emission spectrometer (ICP-OES) (Varian, Australia) using certified standards (Sigma, St. Louis, MO, USA; TraceCERT ${ }^{\circledR}$ ).

\subsection{Statistical Analysis}

All experiments were performed six times independently. For $\mathrm{O}_{2}{ }^{-}$content, cell death, - $\mathrm{OH}$ content and shoot dry weight measurements, 20 individual B. napus seedlings per treatment were analyzed. For all other experiments, 40 B. napus seedling shoots were homogenized in pools of 10 seedlings per treatment. The one-way analysis of variance (ANOVA) test was used for statistical analysis on all data, and means (for six independent experiments) were compared according to the Tukey-Kramer test at a 5\% level of significance using GraphPad Prism 5.03 software.

\section{Results}

\subsection{Exogenous DIM Improves Seed Germination under Vanadium Stress}

We observed increases in B. napus seed germination of $108 \%$ in DIM-treated seeds and $43 \%$ in DIM + vanadium combination-treated seeds when compared to the control seeds (Table 1). A reduction in seed germination of $58 \%$ was observed when seeds were treated with vanadium (Table 1 ). However, seed germination in the presence of DIM + vanadium was increased by $244 \%$ compared to the vanadium-only-treated seeds (Table 1 ).

Table 1. B. napus seed germination in response to control, DIM, vanadium and DIM + vanadium treatments. Data represent the means $( \pm \mathrm{SE})$ of six independent experiments and different letters per row indicate the mean values that are significantly different at $p<0.05$ (Tukey-Kramer test).

\begin{tabular}{ccccc}
\hline & Control & DIM & Vanadium & $\begin{array}{c}\text { DIM + } \\
\text { Vanadium }\end{array}$ \\
\hline Germination \% & $38.50 \pm 4.50^{\mathrm{a}}$ & $80.00 \pm 7.00^{\mathrm{b}}$ & $16.00 \pm 1.50^{\mathrm{c}}$ & $55.00 \pm 4.00^{\mathrm{d}}$ \\
\hline
\end{tabular}

\subsection{Exogenous DIM Improves Seedling Shoot Chlorophyll Content under Vanadium Stress}

DIM treatment led to an increase in B. napus chlorophyll $a$ content of $35 \%$ (Table 2). Vanadium treatment led to a reduction in chlorophyll $a$ content of $21 \%$ (Table 2 ). However, we observed no significant differences in chlorophyll $a$ content in DIM + vanadium combination-treated seedlings (Table 2 ). An increase in chlorophyll $a$ content of $36 \%$ was observed in DIM + vanadium combination-treated seedlings when compared to the vanadium treatment (Table 2). Furthermore, we observed no significant difference in chlorophyll $b$ content in DIM-treated seedlings (Table 2). However, we observed a 35\% reduction in chlorophyll $b$ content in vanadium-treated seedlings (Table 2 ). The DIM + vanadium combination treatment led to a reduction of $21 \%$ in chlorophyll $b$ content (Table 2 ). An increase in chlorophyll $b$ content of $22 \%$ was observed in DIM + vanadium combination-treated seedlings when compared to the vanadium treatments (Table 2). DIM treatment increased the total chlorophyll $(a+b)$ content by $26 \%$ (Table 2 ). A reduction in total chlorophyll content of $26 \%$ was observed in vanadium-treated seedlings (Table 2). However, we observed no significant difference in total chlorophyll content in DIM + vanadium combination treatments (Table 2). An increase in total chlorophyll content of $32 \%$ was observed in 
DIM + vanadium combination-treated seedlings when compared to the vanadium-treated seedlings (Table 2).

Table 2. Chlorophyll concentration in B. napus seedling shoots in response to control, DIM, vanadium and DIM + vanadium treatments. Data represent the means $( \pm S E)$ of six independent experiments and different letters per row indicate the mean values that are significantly different at $p<0.05$ (Tukey-Kramer test).

\begin{tabular}{ccccc}
\hline $\begin{array}{c}\text { Chlorophyll } \\
\left(\boldsymbol{\mu g} \cdot \mathbf{g}^{-\mathbf{1})}\right.\end{array}$ & Control & DIM & Vanadium & $\begin{array}{c}\text { DIM + } \\
\text { Vanadium }\end{array}$ \\
\hline$a$ & $143.36 \pm 15.11^{\mathrm{a}}$ & $194.15 \pm 16.71^{\mathrm{b}}$ & $112.39 \pm 10.45^{\mathrm{c}}$ & $152.50 \pm 11.71^{\mathrm{a}}$ \\
$b$ & $58.81 \pm 3.12^{\mathrm{a}}$ & $61.18 \pm 5,56^{\mathrm{a}}$ & $38.07 \pm 2.61^{\mathrm{b}}$ & $46.61 \pm 2.09^{\mathrm{c}}$ \\
$a+b$ & $202.17 \pm 18.23^{\mathrm{a}}$ & $255.33 \pm 22.27^{\mathrm{b}}$ & $150.46 \pm 13.06^{\mathrm{c}}$ & $199.11 \pm 13.80^{\mathrm{a}}$ \\
\hline
\end{tabular}

\subsection{Exogenous DIM Improves Seedling Shoot Growth and Dry Weight under Vanadium Stress}

An increase in growth was observed after DIM treatment when compared to the control (Figure 1A). A decrease in growth was observed in the vanadium-treated seedlings (Figure 1A). We observed similar growth for the control and DIM + vanadium combination treatment (Figure 1A). An overall increase in growth was observed in the DIM combination treatment with vanadium, when compared to the vanadium-only-treated seedlings (Figure 1A). An increase in B. napus dry weight of 63\% was observed in DIMtreated seedling (Figure 1B). A reduction in dry weight of $38 \%$ was observed in vanadium treatment (Figure 1B). An increase in dry weight of $11 \%$ was observed in DIM + vanadium combination treatments (Figure 1B). Furthermore, an increase in dry weight of $80 \%$ was observed in DIM + vanadium combination-treated seedlings when compared to the vanadium treated seedlings (Figure 1B).

A

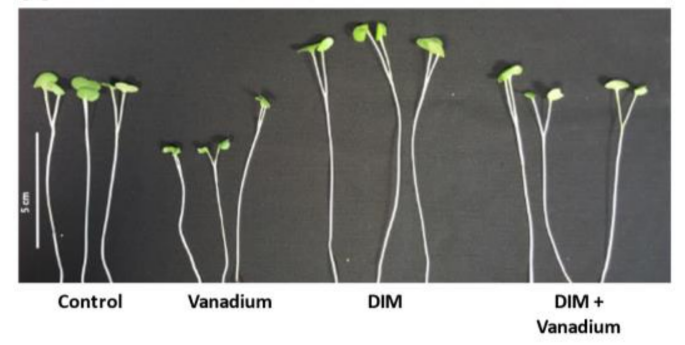

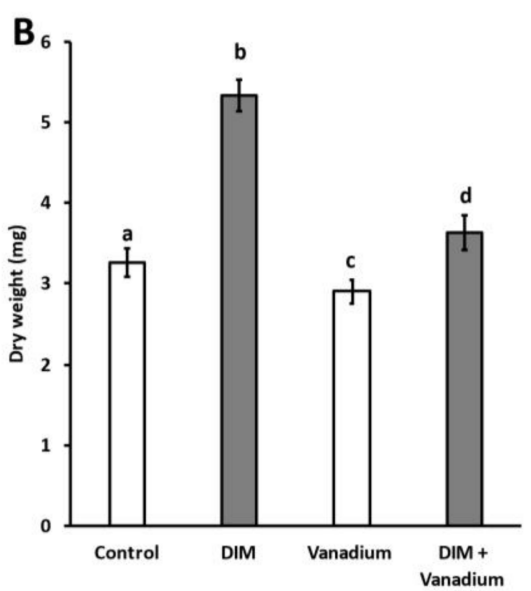

Figure 1. Representative visual image of B. napus seedling shoots (A) and shoot dry weight of seedlings (B) treated with control, DIM, vanadium and DIM + vanadium. Data represent the mean $( \pm \mathrm{SE})$ from six independent experiments and different letters $(\mathrm{a}, \mathrm{b}, \mathrm{c}$ and $\mathrm{d})$ represent statistical significance at $p<0.05$ (Tukey-Kramer test).

\subsection{Exogenous DIM Reduces $\mathrm{O}_{2}{ }^{-}$Content and $\mathrm{H}_{2} \mathrm{O}_{2}$ Content in Seedlings under} Vanadium Stress

We observed increases in $\mathrm{O}_{2}{ }^{-}$content in DIM-treated seedlings (19\%), vanadium treatment $(146 \%)$, and DIM + vanadium combination treatment $(87 \%)$, respectively (Figure $2 \mathrm{~A}$ ). However, a decrease in $\mathrm{O}_{2}{ }^{-}$content of $24 \%$ was observed in DIM + vanadium combination treatment (Figure 2A). Furthermore, we observed increases in $\mathrm{H}_{2} \mathrm{O}_{2}$ content in DIM-treated seedlings (62\%), vanadium-treated seedlings (149\%), and DIM + vanadium combinationtreated seedlings (91\%), respectively (Figure 2B). In addition, a decrease in $\mathrm{H}_{2} \mathrm{O}_{2}$ content 
of $23 \%$ was observed in DIM + vanadium combination treatment when compared to the vanadium treatment (Figure 2B).
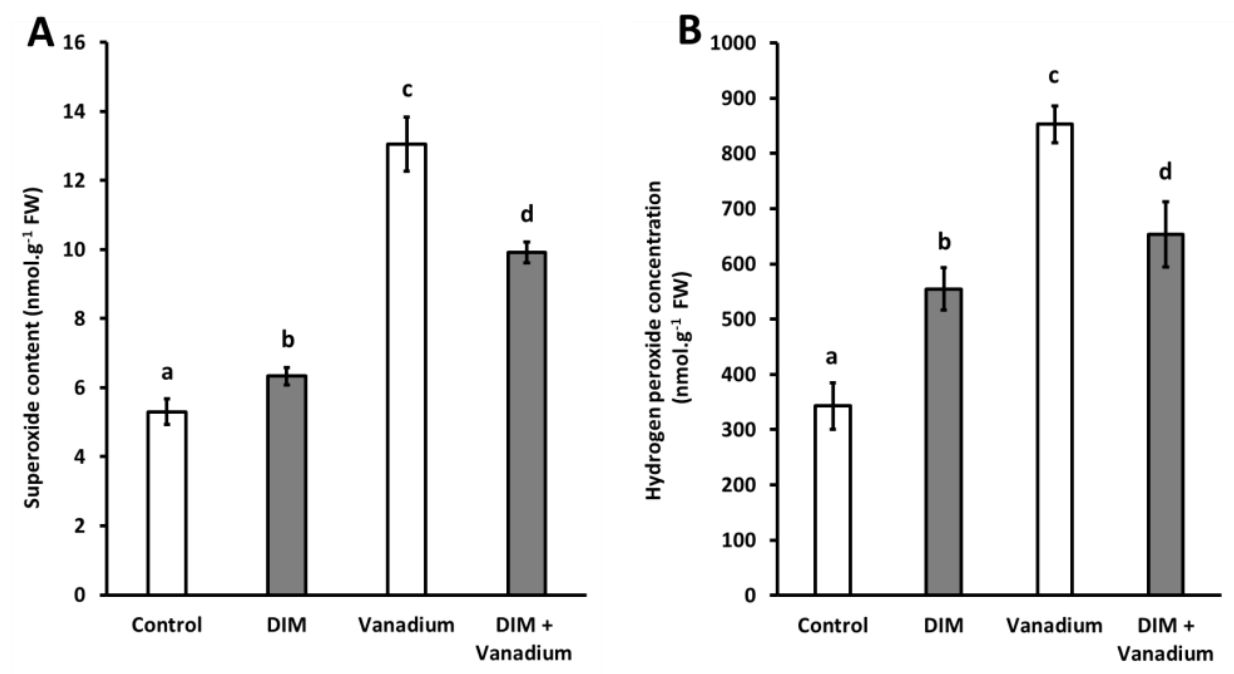

Figure 2. Superoxide content (A) and hydrogen peroxide concentration (B) in B. napus seedling shoots under control, DIM, vanadium and DIM + vanadium treatments. Data represent the mean $( \pm \mathrm{SE})$ of six independent experiments. Different letters (a, b, c and d) represent statistical significance at $p<0.05$ (Tukey-Kramer test).

\subsection{Exogenous DIM Reduces MG Content and .OH Content in Seedlings under Vanadium Stress}

We observed no significant difference in MG content in DIM-treated seedlings (Figure 3A). However, we observed increases in MG content in vanadium-treated seedlings (277\%), and $\mathrm{DIM}+$ vanadium combination-treated seedlings (75\%), respectively (Figure 3A). A decrease in MG content of $54 \%$ was observed in DIM + vanadium combination-treated seedlings when compared to the vanadium treatment (Figure 3A). Furthermore, we observed no significant difference in $\cdot \mathrm{OH}$ content in DIM-treated seedlings (Figure 3B) but we observed increases in $\cdot \mathrm{OH}$ content in vanadium-treated seedlings $(143 \%)$, and DIM + vanadium combination-treated seedlings (15\%), respectively (Figure 3B). A decrease in $\cdot \mathrm{OH}$ content of $53 \%$ was observed in DIM + vanadium combination-treated seedlings when compared to the vanadium treatment (Figure 3B).
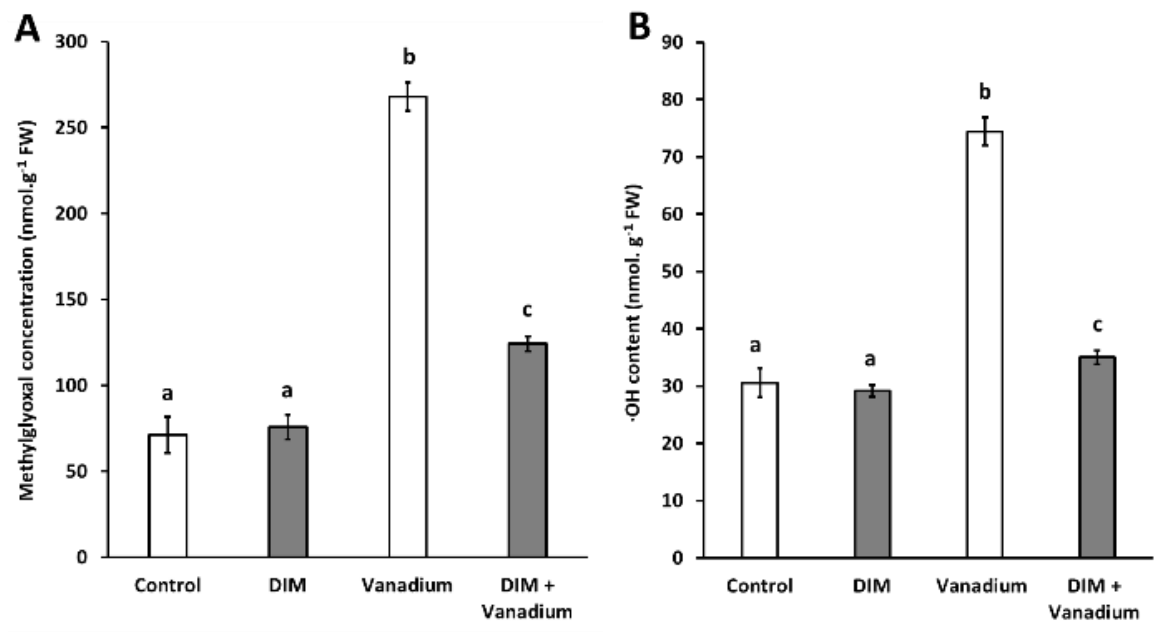

Figure 3. Methylglyoxal content (A) and hydroxyl radical content (B) in B. napus seedling shoots under control, DIM, vanadium and DIM + vanadium treatments. Data represent the mean $( \pm \mathrm{SE})$ of six independent experiments. Different letters $(\mathrm{a}, \mathrm{b}$ and $\mathrm{c})$ represent statistical significance at $p<0.05$ (Tukey-Kramer test). 


\subsection{DIM Reduces $M D A$ and $C D$ in Seedlings under Vanadium Stress}

We observed no significant difference in MDA content in DIM-treated seedlings (Figure 4A). An increase in MDA content of $99 \%$ was observed in vanadium treatment (Figure $4 \mathrm{~A}$ ). An increase in MDA content of $71 \%$ was observed in DIM + vanadium combination treated seedlings (Figure 4A). A decrease in MDA content of $14 \%$ was observed in DIM + vanadium combination treatments when compared to the vanadium-treated seedlings (Figure 4A). Furthermore, no significant difference in CD content was observed in DIM-treated seedlings (Figure 4B). An increase in CD content of $185 \%$ was observed in the vanadium treatment (Figure 4B). An increase in CD content of $60 \%$ was observed in DIM + vanadium combination-treated seedlings (Figure 4B). Furthermore, a decrease in CD content of $44 \%$ was observed in DIM + vanadium combination treatment when compared to the vanadium-treated seedlings (Figure 4B).
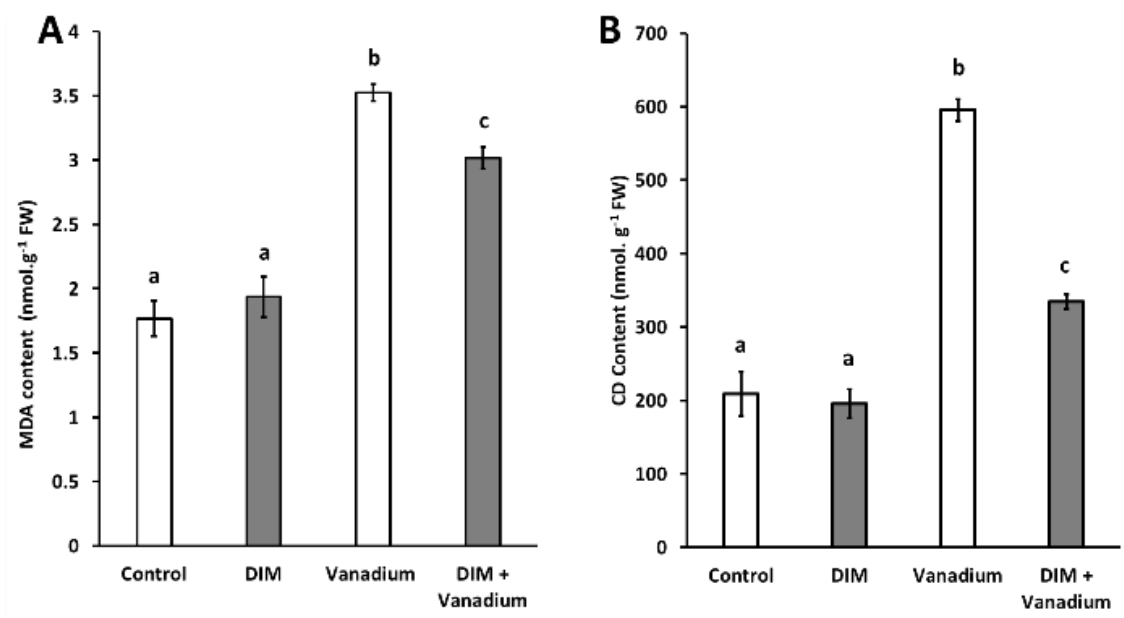

Figure 4. Malondialdehyde (MDA) content (A) and conjugated diene (CD) content (B) in B. napus seedling shoots under control, DIM, vanadium and DIM + vanadium treatments. Data represent the mean $( \pm \mathrm{SE})$ of six independent experiments. Different letters $(\mathrm{a}, \mathrm{b}$ and $\mathrm{c})$ represent statistical significance at $p<0.05$ (Tukey-Kramer test).

\subsection{Exogenous DIM Increases SOD Activity and APX Activity in Seedlings under Vanadium Stress}

We observed increases in superoxide dismutase activities in DIM-treated seedlings $(44 \%)$, vanadium-treated seedlings $(28 \%)$, and DIM + vanadium combination-treated seedlings (45\%), respectively (Figure 5A). An increase in superoxide dismutase activity of $13 \%$ was observed in DIM + vanadium combination treatments when compared to the vanadium-treated seedlings (Figure 5A). Furthermore, we observed increases in ascorbate peroxidase activities in DIM-treated seedlings (19\%), vanadium-treated seedlings $(69 \%)$, and DIM + vanadium combination-treated seedlings (152\%), respectively (Figure 5B). An increase in ascorbate peroxidase activity of $49 \%$ was observed in DIM + vanadium combination treatment when compared to the vanadium-treated seedlings (Figure 5B). 

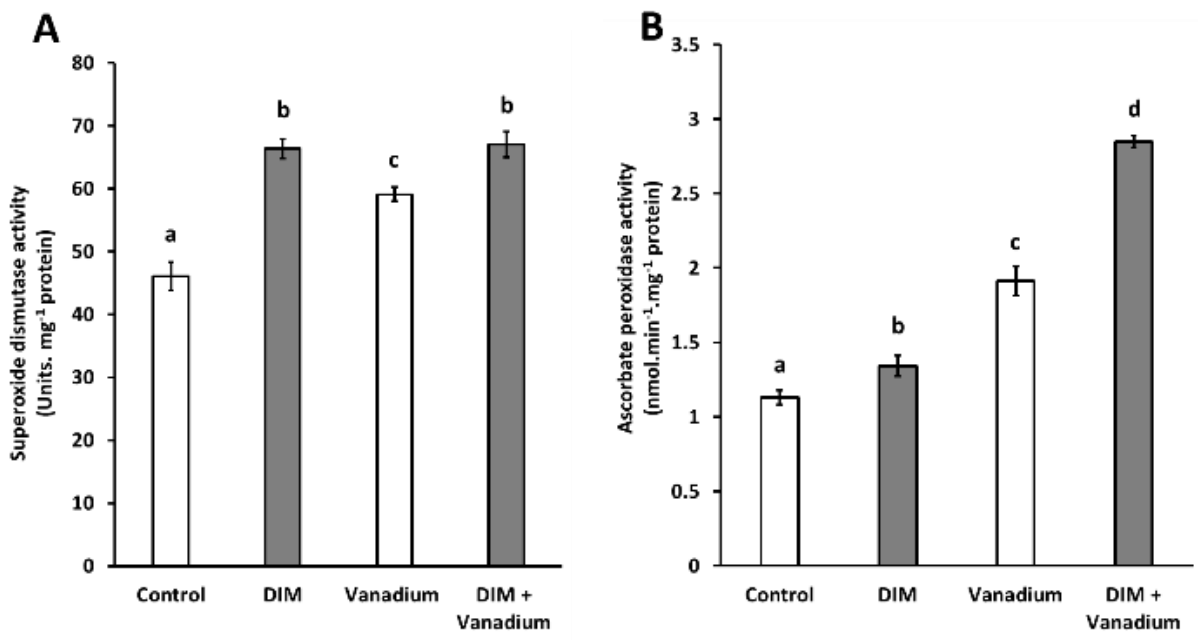

Figure 5. Superoxide dismutase (SOD) activity (A) and ascorbate peroxidase (APX) activity (B) in B. napus seedling shoots under control, DIM, vanadium and DIM + vanadium treatments. Data represent the mean $( \pm \mathrm{SE})$ of six independent experiments. Different letters (a, b, c and d) represent statistical significance at $p<0.05$ (Tukey-Kramer test).

\subsection{Exogenous DIM Increases Gly I Activity and GST Activity in Seedlings Shoots under Vanadium Stress}

No significant difference in Gly I activity was observed in DIM-treated seedlings (Figure 6A). A decrease in Gly I activity of $65 \%$ was observed in vanadium-treated seedlings (Figure 6A). A decrease in Gly I activity of $25 \%$ was observed in DIM + vanadium combination treatment, when compared to the control (Figure 6A). Furthermore, an increase in Gly I activity of $113 \%$ was observed in DIM + vanadium combination treatment when compared to the vanadium-treated seedlings (Figure 6A). Furthermore, we observed increases in GST activities in DIM-treated seedlings (52\%), vanadium treated seedlings $(79 \%)$, and DIM + vanadium combination-treated seedlings (161\%), respectively (Figure 6B). An increase in ascorbate peroxidase activity of $46 \%$ was observed in DIM + vanadium combination-treated seedlings when compared to the vanadium treatment (Figure 6B).
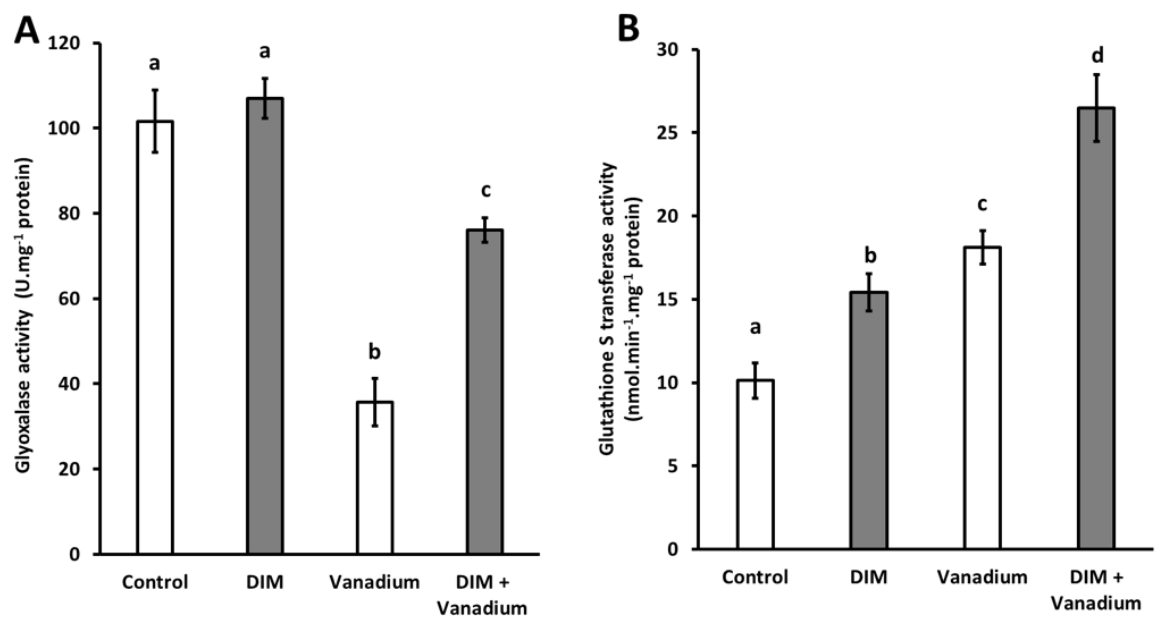

Figure 6. Gly I activity (A) and glutathione S-transferase (GST) activity (B) in B. napus seedling shoots under control, DIM, vanadium and DIM + vanadium treatments. Data represent the mean $( \pm S E)$ of six independent experiments. Different letters ( $a, b, c$ and d) represent statistical significance at $p<0.05$ (Tukey-Kramer test). 


\subsection{Exogenous DIM Reduces Seedling Shoot Cell Death under Vanadium Stress}

No significant difference in shoot Evans blue uptake was observed in the DIM treatments (Figure 7). An increase in Evans blue uptake of 39\% was observed in vanadiumtreated seedlings (Figure 7). An increase in Evans blue uptake of $11 \%$ was observed in DIM + vanadium combination treatment (Figure 7). Furthermore, a decrease in Evans blue uptake of $20 \%$ was observed in DIM + vanadium combination-treated seedlings when compared to the vanadium treatment (Figure 7).

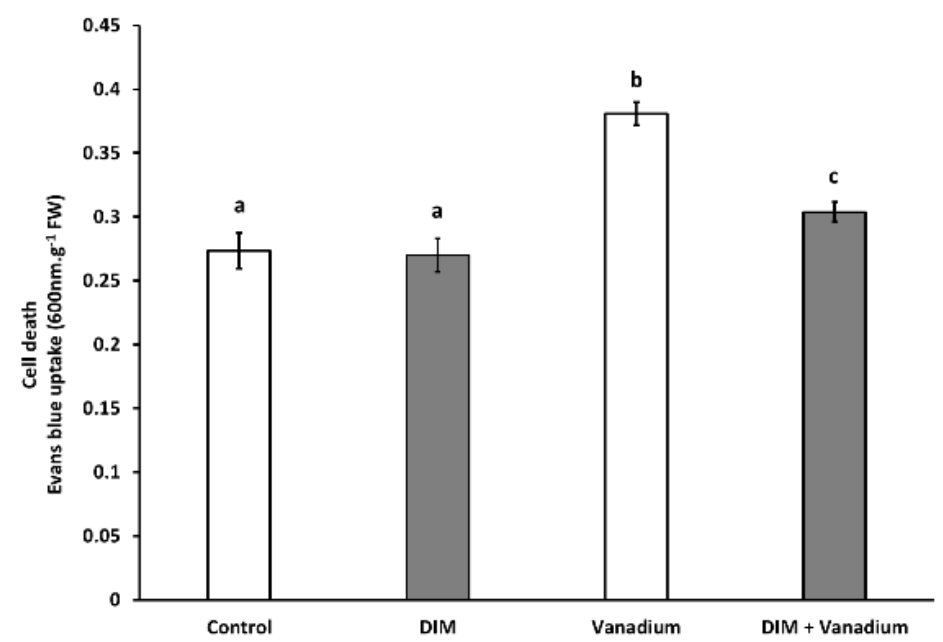

Figure 7. Seedling shoot Evans blue uptake (cell death) after control, DIM, vanadium and DIM + vanadium treatments. All the values are mean $( \pm \mathrm{SE})$ from six independent experiments. Different letters ( $\mathrm{a}, \mathrm{b}$ and $\mathrm{c}$ ) differ significantly at $p<0.05$ according to the Tukey-Kramer test.

\subsection{Exogenous DIM Does Not Reduce Seedling Shoot Vanadium Content under Vanadium Stress}

No significant difference in vanadium content was observed in DIM-treated seedlings when compared to the control (Figure 8). An increase in vanadium content of $153 \%$ was observed in vanadium-treated seedlings (Figure 8 ). An increase in vanadium content of $136 \%$ was observed in DIM + vanadium combination-treated seedlings when compared to the control (Figure 8). Furthermore, no significant difference was observed in vanadium content in DIM + vanadium combination treatment and the vanadium-only treatment (Figure 8).

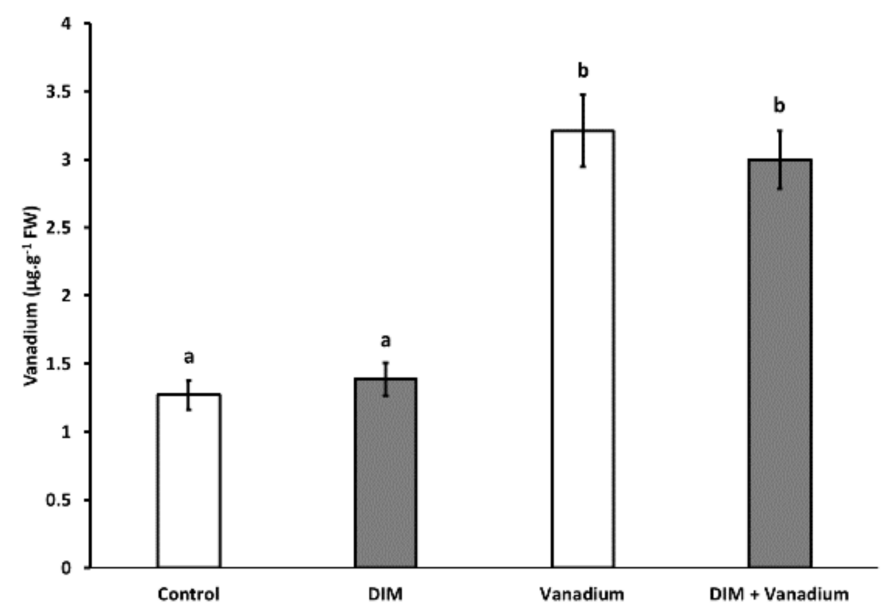

Figure 8. Seedling shoot vanadium content after control, DIM, vanadium and DIM + vanadium treatments. All the values are mean $( \pm \mathrm{SE})$ from six independent experiments. Different letters $(\mathrm{a}, \mathrm{b})$ differ significantly at $p<0.05$ according to the Tukey-Kramer test. 


\section{Discussion}

Our previous study showed that $B$. napus growth and development were affected by treatment with $350 \mu \mathrm{M}$ of vanadium [11]. In another study, we showed that $15 \mu \mathrm{M}$ of DIM could improve B. napus seedling shoot growth through the activation of ROS signaling pathways in the absence of stress [34]. Therefore, the aim of the present study was to document the effects of exogenous DIM on vanadium toxicity responses in B. napus using the vanadium-sensitive cultivar AV Garnet at the early seedling stage.

In this study, we observed an increase in seed germination after DIM treatment. Vanadium treatment led to a decrease in germination percentage and this result was in agreement with the observations of Wu et al. [48], in which Medicago sativa seed germination was decreased by vanadium treatment $\left(50 \mathrm{mg} \cdot \mathrm{L}^{-1}\right)$. However, in our study, the DIM and vanadium combination treatment improved seed germination when compared to the vanadium-only-treated seeds. Furthermore, we observed taller seedling shoots after DIM treatment when compared to the control and this result agrees with our previous findings [34]. We observed stunting of seedling shoots at the harvesting stage following vanadium treatment. This result agreed with the observations of Tham et al. [49], in which seedling shoot growth was inhibited in H. vulgare, Triticum aestivum, G. max and O. sativa following vanadium treatment. In this study, however, DIM treatment showed improved seedling shoot growth even in the presence of vanadium. In addition, DIM treatment led to an increase in seedling shoot biomass (dry weight). We also observed a decrease in seedling shoot biomass in the vanadium-only-treated seedlings and this result agreed with the observations of Nawaz et al. [18], in which C. lanatus seedling biomass decreased in response to vanadium treatment. However, in our study, we observed an improvement in biomass in the DIM and vanadium combination treatment when compared to the vanadium-only treatment. Our observations of improved seedling shoot growth in the DIM-only and the combination treatment could be attributed to the fact that we also observed an increase in chlorophyll $a$, chlorophyll $b$ and total chlorophylls in the DIM-only and the DIM and vanadium combination treatment when compared to the vanadium-only treatment. In the literature, a direct correlation between chlorophyll content and biomass exists in plants [42,50], and Nawaz et al. [18] also observed a direct correlation between biomass improvement and chlorophylls in a melatonin and vanadium combination treatment compared to vanadium-only treatment in C. lanatus seedlings. In addition, DIM, as a glucosinolate molecule, could also hypothetically interact directly with the chlorophyll $a$ molecule and possibly lead to an increase in chlorophyll $a$ content. This hypothesis is supported by Gielen et al. [51], who observed an increase in chlorophyll $a$ in a $B$. napus cultivar with higher glucosinolate content.

Vanadium toxicity leads to the generation of toxic reactive molecules, which ultimately lead to plant cell death [11,52]. At moderate levels, these reactive molecules can also prime scavenging enzymes and thus the careful control of reactive compounds could be an attractive strategy to improve plant performance under vanadium stress [18]. Therefore, in this study we measured reactive oxygen species $\left(\mathrm{O}_{2}{ }^{-}, \mathrm{H}_{2} \mathrm{O}_{2}\right.$ and $\left.\cdot \mathrm{OH}\right)$ as well as the reactive dicarbonyl compound MG. In this study, DIM treatment led to an increase in $\mathrm{O}_{2}{ }^{-}$ and $\mathrm{H}_{2} \mathrm{O}_{2}$ content and no change in $\cdot \mathrm{OH}$ content. In addition, we observed no change in MG content after DIM treatment and this result suggests that there is no interplay between DIM and MG under non-abiotic stress (control) conditions in B. napus. We also observed an increase in the concentrations of $\mathrm{O}_{2}{ }^{-}, \mathrm{H}_{2} \mathrm{O}_{2}, \cdot \mathrm{OH}$ and $\mathrm{MG}$ following vanadium treatment. Vanadium treatment also increased the $\mathrm{O}_{2}{ }^{-}$content of $\mathrm{AV}$ Garnet leaves in our previous study [11], which is in agreement with the findings in the current study. An increase in $\mathrm{H}_{2} \mathrm{O}_{2}$ content in C. lanatus seedlings was also observed by Nawaz et al. [18] following vanadium treatment, which is in agreement with the findings in our study. Even though no direct link exists between $\cdot \mathrm{OH}$ and vanadium stress in the literature, it is well known that other heavy metals trigger an increase in toxic $\cdot \mathrm{OH}$ content in plants $[53,54]$. In addition, there are also no published data which suggest that vanadium stress leads to an increase in MG content in plants. However, it is well documented that other heavy metals increase MG 
content and this lead to cellular damage and cell death [28,55]. We also observed a decrease in the concentrations of $\mathrm{O}_{2}{ }^{-}, \mathrm{H}_{2} \mathrm{O}_{2}, \cdot \mathrm{OH}$ and $\mathrm{MG}$ in the DIM and vanadium combination treatment when compared to the vanadium-only treatments. This result suggests that exogenous DIM decreased the toxicity of reactive compounds under vanadium stress, therefore leading to improved photosynthetic metabolism and ultimately an increase in biomass in B. napus. A similar observation was made by Mahmud et al. [28], in which the molecule GABA reduced all reactive compounds $\left(\mathrm{O}_{2}{ }^{-}, \mathrm{H}_{2} \mathrm{O}_{2}, \cdot \mathrm{OH}\right.$ and $\left.\mathrm{MG}\right)$ through priming of scavenging enzymes to confer chromium stress tolerance in $B$. juncea.

Heavy metal toxicity, which results in an increase in reactive compounds, often leads to lipid peroxidation. Therefore, the extent of lipid peroxidation in plants can be assessed by measuring the levels of MDA and CD, respectively [56]. In our study, DIM treatment led to no change in MDA and CD content, which suggests that exogenous DIM does not lead to changes in MDA and CD content, potentially as a result of unchanged $\cdot \mathrm{OH}$ content under DIM treatment. Furthermore, we observed an increase in both MDA and CD content in vanadium-only-treated seedlings. The result for the increased MDA content under vanadium stress is in agreement with our previous findings [11], but no direct link exists in the literature between vanadium stress and increases in CD content in plants. Nevertheless, it is observed in the literature that other heavy metals trigger an increase in CD content in plants [57]. A direct link was also observed between $\cdot \mathrm{OH}$ content and lipid peroxidation marker content (MDA and CD) in lead-treated Triticum aestivum by Kaur et al. [57], which is in agreement with our observations. We also observed a decrease in both MDA and CD content in the DIM and vanadium combination treatment when compared to the vanadiumonly treatments. We hypothesize that DIM lowers lipid peroxidation by decreasing $\cdot \mathrm{OH}$ content in $B$. napus under vanadium stress. Ali et al. [58] indicated that $\cdot \mathrm{OH}$ triggers the initiation step of the three-step lipid peroxidation reaction in plants by removing hydrogen atoms from fatty acids. Therefore, less lipid peroxidation is expected when the $\cdot \mathrm{OH}$ content is decreased. This result was also observed by Kaur et al. [57], when sodium nitroprusside (nitric oxide donor) application reduced lipid peroxidation (MDA and CD content) by decreasing $\cdot \mathrm{OH}$ content under lead stress.

Enzymes are required to scavenge reactive molecules and to limit cell death in plants under heavy metal stress $[11,18]$. Therefore, in this study we investigated the regulation of SOD $\left(\mathrm{O}_{2}{ }^{-}\right.$scavenger), APX ( $\mathrm{H}_{2} \mathrm{O}_{2}$ scavenger), Gly I (MG scavenger) and GST (which scavenges organic hydroperoxides through glutathione-dependent isomerizations) under DIM, vanadium and DIM and vanadium combination treatments. DIM treatment led to an increase in SOD and APX activity. Furthermore, we observed no change in Gly I activity in the DIM-only-treated seedlings and thus we hypothesize that the unchanged MG content under DIM-only treatment led to no activation of Gly I. We also observed an increase in GST activity under DIM-only treatment when compared to the control. We postulate that the GST activity might be triggered directly by the DIM-only treatment. This hypothesis will require further investigation, although studies have shown that the glucosinolate molecule allyl isothiocyanate can increase GST activity in plants following exogenous application $[59,60]$. We also observed an increase in SOD and APX activity in the vanadium-treated seedlings. A SOD activity increase was also observed by Altaf et al. [61] in O. sativa treated with vanadium and an increase in APX activity was also observed in vanadium-treated $M$. sativa by Wu et al. [48]. The SOD activity increase in this study is also in contradiction with our results from the previous study, in which vanadium stress inhibited SOD activity in more mature AV Garnet leaves [11]. We hypothesize that the difference in results is due to growth stage differences in the two studies at the point of harvesting. In this study, we analyzed SOD activity at the seedling stage, whereas in Gokul et al. [11] we analyzed SOD activity in the leaves at the rosette stage. Our hypothesis is supported by Shah et al. [62], who observed that SOD activity decreased over time in O. sativa (cultivar Jaya) growth under Cadmium stress. In addition, we observed a decrease in Gly I activity following vanadium treatment. There is no published literature which shows that vanadium treatment leads to inhibition of Gly I activity in 
plants. However, Hasanuzzaman et al. [63] also observed a decrease in Gly I activity in B. napus treated with cadmium, which suggests that metals can inhibit Gly I activity. The inhibition of Gly I in our study under vanadium stress could explain the significant increase which we observed in the MG content following vanadium treatment. We also observed an increase in GST activity in plants treated with vanadium. We postulate that vanadium treatment could induce the transcription of GST genes, and this hypothesis is supported by findings of Lin et al. [64], in which vanadium stress induced transcription of 11 GST genes in O. sativa. In this study, we observed an increase in SOD, APX, Gly I and GST activities in the DIM and vanadium combination treatment when compared to the vanadium-only treatment. The capacity to control oxidative stress by antioxidant enzymes leads to much better plant growth under stress conditions [65]. Therefore, we suggest that the decreases observed in reactive compound contents in this study in response to the DIM and vanadium combination treatment is as a consequence of increases in SOD, APX, Gly I and GST activities in the combination treatment.

Continuous lipid peroxidation induces plasma membrane injuries under heavy metal stress, and this subsequently leads to a decrease in cell viability [66]. Therefore, to study cell viability changes in plants, Evans blue dye is used to measure membrane integrity. Plant cells with damaged membranes do not exclude the dye and therefore stain blue [67]. Therefore, in our study, we measured Evans blue uptake in the seedling shoots of B. napus (cultivar AV Garnet) following DIM, vanadium and DIM and vanadium combination treatments. We observed no change in Evans blue uptake in the DIM-only treatments and this finding was also observed in our previous study [11]. Furthermore, we observed an increase in Evans blue uptake in the vanadium-only treatments, and this finding was supported by the study of Imtiaz et al. [52]. We also observed a decrease in Evans blue uptake in the DIM and vanadium combination treatment when compared to the vanadiumonly treatment. We postulate that DIM treatment increased SOD, APX, Gly I and GST activities under vanadium stress, which led to a decrease in toxic reactive compounds. Furthermore, the decrease in toxic reactive compounds under DIM treatment led to a decrease in lipid peroxidation, which subsequently improved the membrane integrity under vanadium stress, and this led to less uptake of Evans blue when compared to the vanadium-only-treated seedlings.

Plants possess finely tuned mechanisms which allow them to survive under heavy metal stress conditions. Plants avoid metal uptake from the surroundings or exclude it during the initial uptake process [68]. The metals which bypass the exclusion step are chelated or sequestered in order to prevent metal movement from roots into shoots [69]. In this study, we measured the vanadium content in B. napus seedlings shoots following treatment with DIM, vanadium and DIM and vanadium combination treatments. We observed no changes in the DIM-only treatment. This result suggests that DIM application does not change vanadium uptake from control soil environments. Furthermore, vanadium treatment led to an increase in seedling shoot vanadium content, and this result was also observed in our previous study, Gokul et al. [11], in which vanadium treatment led to an increase in vanadium content in $B$. napus. We also observed no change in vanadium content when we compared the DIM and vanadium combination treatment with the vanadiumonly treatment. Because DIM treatment did not change vanadium content regulation mechanisms under normal conditions, our results suggest that there was also no regulation of vanadium uptake mechanisms under increased vanadium treatment in B. napus in the presence of DIM.

\section{Conclusions}

In conclusion, our results suggest that exogenous DIM treatments can enhance the vanadium stress tolerance of a vanadium-sensitive B. napus cultivar, AV Garnet, at the seed germination and seedling development stage. DIM treatment did not alter vanadium content in the combination treatment, which suggests that the triggered signaling events are crucial for the DIM-induced tolerance in the seedling shoots. Under vanadium stress, 
DIM application led to an increase in SOD, APX, Gly I and GST enzymatic activities, which led to a decrease in reactive compounds $\left(\mathrm{O}_{2}{ }^{-}, \mathrm{H}_{2} \mathrm{O}_{2}, \cdot \mathrm{OH}\right.$ and $\left.\mathrm{MG}\right)$. The decrease in reactive compounds led to an improvement of the chlorophylls in the combination treatment. In addition, a much lower amount of reactive compounds led to a decrease in lipid peroxidation (MDA and CD content), to a decrease in cell death and ultimately to an improvement in seedling shoot growth. To our knowledge, this is the first report which indicates a positive functional role for DIM under vanadium stress in plants using pot experiments. This study highlights the potential signaling role of DIM in the regulation of ROS under vanadium stress at the early seedling development stage. A limitation of the study is that it studies only the shoot response. Therefore, future work should focus on non-soil experiments in order to analyze the root response. Further use of omics tools (transcriptomics and proteomics) could identify crucial molecular targets of DIM in Brassica plants and subsequently improve our understanding of DIM signaling in the near future.

Author Contributions: Conceptualization, M.K. and A.G.; methodology, A.G., M.F.C., L.-A.N., A.K., N.L., D.M.-C. and M.K.; investigation, A.G.; data curation, A.G., M.F.C., L.-A.N.; writing-original draft preparation, A.G.; writing-review and editing, A.G., M.F.C., L.-A.N., A.K., N.L., D.M.-C. and M.K.; supervision, A.K., N.L., D.M.-C. and M.K.; project administration, M.K.; funding acquisition, M.K. and A.K. All authors have read and agreed to the published version of the manuscript.

Funding: L.N. and M.F.C. were funded by the National Research Foundation of South Africa (NRF). D.M.C. laboratory is supported by the US National Science Foundation (IOS-1734145 and MCB1818312). This research was financially supported by the NRF to M.K. (Grant numbers: 116346 and 109083) and A.K. (Grant numbers: 107023 and 115280). Part of the research was funded by a DST-NRF Centre of Excellence in Food Security award (Project ID: 170202) as well as GrainSA (GB0200066).

Data Availability Statement: The data presented in this study are available in the published manuscript.

Acknowledgments: The authors would like to thank various institutions, namely, the University of the Western Cape, the University of Free State and the University of Missouri (Columbia) for infrastructure and administrative support.

Conflicts of Interest: The authors declare no conflict of interest. The funders had no role in the design of the study; in the collection, analyses, or interpretation of data; in the writing of the manuscript, or in the decision to publish the results.

\section{References}

1. An, H.; Qi, X.; Gaynor, M.L.; Hao, Y.; Gebken, S.C.; Mabry, M.E.; McAlvay, A.C.; Teakle, G.R.; Conant, G.C.; Barker, M.S.; et al. Transcriptome and organellar sequencing highlights the complex origin and diversification of allotetraploid Brassica napus. Nat. Commun. 2019, 10, 1-12. [CrossRef]

2. Maheshwari, P.; Kovalchuk, I. Genetic transformation of crops for oil production. In Industrial Oil Crops; McKeon, T.A., Hayes, D.G., Hildebrand, D.F., Weselake, R.J., Eds.; AOCS Press: Urbana, IL, USA, 2016; pp. 379-412.

3. Ahmadi, F.I.; Karimi, K.; Struik, P.C. Effect of exogenous application of methyl jasmonate on physiological and biochemical characteristics of Brassica napus L. cv. Talaye under salinity stress. S. Afr. J. Bot. 2018, 115, 5-11. [CrossRef]

4. Zheng, B.; Li, H.; Zhang, J.; Chai, L.; Pu, X.; Jiang, J.; Cui, C.; Jiang, L. Effects of cadmium stress on seed germination and seedling growth of Brassica napus L. Agric. Sci. Technol. 2017, 18, 591-601.

5. Ferreyroa, G.V.; Lagorio, M.G.; Trinelli, M.A.; Lavado, R.S.; Molina, F.V. Lead effects on Brassica napus photosynthetic organs. Ecotoxicol. Environ. Saf. 2017, 140, 123-130. [CrossRef] [PubMed]

6. Farooq, M.A.; Islam, F.; Yang, C.; Nawaz, A.; Gill, R.A.; Ali, B.; Song, W.; Zhou, W. Methyl jasmonate alleviates arsenicinduced oxidative damage and modulates the ascorbate-glutathione cycle in oilseed rape roots. Plant Growth Regul. 2018, 84, 135-148. [CrossRef]

7. Nafees, M.; Ali, S.; Naveed, M.; Rizwan, M. Efficiency of biogas slurry and Burkholderia phytofirmans PsJN to improve growth, physiology, and antioxidant activity of Brassica napus L. in chromium-contaminated soil. Environ. Sci. Pollut. Res. 2018, 25, 6387-6397. [CrossRef]

8. Shen, Q.I.; Jiang, M.; Li, H.U.A.; Che, L.L.; Yang, Z.M. Expression of a Brassica napus heme oxygenase confers plant tolerance to mercury toxicity. Plant Cell Environ. 2011, 34, 752-763. [CrossRef] [PubMed]

9. Kazemi, N.; Khavari-Nejad, R.A.; Fahimi, H.; Saadatmand, S.; Nejad-Sattari, T. Effects of exogenous salicylic acid and nitric oxide on lipid peroxidation and antioxidant enzyme activities in leaves of Brassica napus L. under nickel stress. Sci. Hortic. 2010, 126, 402-407. [CrossRef] 
10. Zaheer, I.E.; Ali, S.; Rizwan, M.; Farid, M.; Shakoor, M.B.; Gill, R.A.; Najeeb, U.; Iqbal, N.; Ahmad, R. Citric acid assisted phytoremediation of copper by Brassica napus L. Ecotoxicol. Environ. Saf. 2015, 120, 310-317. [CrossRef]

11. Gokul, A.; Cyster, L.F.; Keyster, M. Efficient superoxide scavenging and metal immobilization in roots determines the level of tolerance to vanadium stress in two contrasting Brassica napus genotypes. S. Afr. J. Bot. 2018, 119, 17-27. [CrossRef]

12. Amorim, F.A.; Welz, B.; Costa, A.C.; Lepri, F.G.; Vale, M.G.R.; Ferreira, S.L. Determination of vanadium in petroleum and petroleum products using atomic spectrometric techniques. Talanta 2007, 72, 349-359. [CrossRef]

13. Imtiaz, M.; Rizwan, M.S.; Xiong, S.; Li, H.; Ashraf, M.; Shahzad, S.M.; Shahzad, M.; Rizwan, M.; Tu, S. Vanadium, recent advancements and research prospects: A review. Environ. Int. 2015, 80, 79-88. [CrossRef] [PubMed]

14. Lazaridis, N.K.; Jekel, M.; Zouboulis, A.I. Removal of Cr (VI), Mo (VI), and V (V) ions from single metal aqueous solutions by sorption or nanofiltration. Sep. Sci. Technol. 2003, 38, 2201-2219. [CrossRef]

15. Teng, Y.; Ni, S.; Zhang, C.; Wang, J.; Lin, X.; Huang, Y. Environmental geochemistry and ecological risk of vanadium pollution in Panzhihua mining and smelting area, Sichuan, China. Chin. J. Geochem. 2006, 25, 379-385. [CrossRef]

16. Imtiaz, M.; Mushtaq, M.A.; Rizwan, M.S.; Arif, M.S.; Yousaf, B.; Ashraf, M.; Shuanglian, X.; Rizwan, M.; Mehmood, S.; Tu, S. Comparison of antioxidant enzyme activities and DNA damage in chickpea (Cicer arietinum L.) genotypes exposed to vanadium. Environ. Sci. Pollut. Res. 2016, 23, 19787-19796. [CrossRef]

17. Yang, J.; Wang, M.; Jia, Y.; Gou, M.; Zeyer, J. Toxicity of vanadium in soil on soybean at different growth stages. Environ. Pollut. 2017, 231, 48-58. [CrossRef]

18. Nawaz, M.A.; Jiao, Y.; Chen, C.; Shireen, F.; Zheng, Z.; Imtiaz, M.; Bie, Z.; Huang, Y. Melatonin pretreatment improves vanadium stress tolerance of watermelon seedlings by reducing vanadium concentration in the leaves and regulating melatonin biosynthesis and antioxidant-related gene expression. J. Plant Physiol. 2018, 220, 115-127. [CrossRef]

19. Saco, D.; Martín, S.; San Jose, P. Vanadium distribution in roots and leaves of Phaseolus vulgaris: Morphological and ultrastructural effects. Biol. Plant. 2013, 57, 128-132. [CrossRef]

20. Olness, A.; Gesch, R.; Forcella, F.; Archer, D.; Rinke, J. Importance of vanadium and nutrient ionic ratios on the development of hydroponically grown cuphea. Ind. Crops Prod. 2005, 21, 165-171. [CrossRef]

21. Tanyolac, D.; Ekmekçi, Y.; Ünalan, Ş. Changes in photochemical and antioxidant enzyme activities in maize (Zea mays L.) leaves exposed to excess copper. Chemosphere 2007, 67, 89-98. [CrossRef]

22. Parveen, A.; Saleem, M.H.; Kamran, M.; Haider, M.Z.; Chen, J.T.; Malik, Z.; Rana, M.S.; Hassan, A.; Hur, G.; Javed, M.T.; et al. Effect of citric acid on growth, ecophysiology, chloroplast ultrastructure, and phytoremediation potential of jute (Corchorus capsularis L.) seedlings exposed to copper stress. Biomolecules 2020, 10, 592. [CrossRef]

23. Hoque, T.S.; Hossain, M.A.; Mostofa, M.G.; Burritt, D.J.; Fujita, M.; Tran, L.S.P. Methylglyoxal: An emerging signaling molecule in plant abiotic stress responses and tolerance. Front. Plant Sci. 2016, 7, 1341. [CrossRef]

24. Li, Z.G. Methylglyoxal and glyoxalase system in plants: Old players, new concepts. Bot. Rev. 2016, 82, 183-203. [CrossRef]

25. Meng, H.; Hua, S.; Shamsi, I.H.; Jilani, G.; Li, Y.; Jiang, L. Cadmium-induced stress on the seed germination and seedling growth of Brassica napus L., and its alleviation through exogenous plant growth regulators. Plant Growth Regul. 2009, 58, 47-59. [CrossRef]

26. Bless, Y.; Ndlovu, L.; Gokul, A.; Keyster, M. Exogenous methylglyoxal alleviates zirconium toxicity in Brassica rapa L. seedling shoots. S. Afr. J. Bot. 2017, 100, 327. [CrossRef]

27. Fu, M.M.; Dawood, M.; Wang, N.H.; Wu, F. Exogenous hydrogen sulfide reduces cadmium uptake and alleviates cadmium toxicity in barley. Plant Growth Regul. 2019, 89, 227-237. [CrossRef]

28. Mahmud, J.A.; Hasanuzzaman, M.; Nahar, K.; Rahman, A.; Hossain, M.S.; Fujita, M. $\gamma$-aminobutyric acid (GABA) confers chromium stress tolerance in Brassica juncea L. by modulating the antioxidant defense and glyoxalase systems. Ecotoxicology 2017, 26, 675-690. [CrossRef]

29. Islam, M.M.; Hoque, M.A.; Okuma, E.; Banu, M.N.A.; Shimoishi, Y.; Nakamura, Y.; Murata, Y. Exogenous proline and glycinebetaine increase antioxidant enzyme activities and confer tolerance to cadmium stress in cultured tobacco cells. J. Plant Physiol. 2009, 166, 1587-1597. [CrossRef] [PubMed]

30. Hossain, M.A.; Hasanuzzaman, M.; Fujita, M. Up-regulation of antioxidant and glyoxalase systems by exogenous glycinebetaine and proline in mung bean confer tolerance to cadmium stress. Physiol. Mol. Biol. Plants 2010, 16, 259-272. [CrossRef] [PubMed]

31. Ali, B.; Tao, Q.; Zhou, Y.; Gill, R.A.; Ali, S.; Rafiq, M.T.; Xu, L.; Zhou, W. 5-Aminolevolinic acid mitigates the cadmium-induced changes in Brassica napus as revealed by the biochemical and ultra-structural evaluation of roots. Ecotoxicol. Environ. Saf. 2013, 92, 271-280. [CrossRef] [PubMed]

32. Song, J.; Markewitz, D.; Wu, S.; Sang, Y.; Duan, C.; Cui, X. Exogenous oxalic acid and citric acid improve lead (Pb) tolerance of Larix olgensis A. Henry seedlings. Forests 2018, 9, 510. [CrossRef]

33. Del Carmen Martínez-Ballesta, M.; Moreno, D.A.; Carvajal, M. The physiological importance of glucosinolates on plant response to abiotic stress in Brassica. Int. J. Mol. Sci. 2013, 14, 11607-11625. [CrossRef] [PubMed]

34. Gokul, A.; Roode, E.; Klein, A.; Keyster, M. Exogenous 3, 3'-diindolylmethane increases Brassica napus L. seedling shoot growth through modulation of superoxide and hydrogen peroxide content. J. Plant Physiol. 2016, 196, 93-98. [CrossRef]

35. Pal, C.; Dey, S.; Mahato, S.K.; Vinayagam, J.; Pradhan, P.K.; Giri, V.S.; Jaisankar, P.; Hossain, T.; Baruri, S.; Ray, D.; et al. Eco-friendly synthesis and study of new plant growth promoters: 3, 3'-Diindolylmethane and its derivatives. Bioorganic Med. Chem. Lett. 2007, 17, 4924-4928. [CrossRef] 
36. Nxele, X.; Klein, A.; Ndimba, B.K. Drought and salinity stress alters ROS accumulation, water retention, and osmolyte content in sorghum plants. S. Afr. J. Bot. 2017, 108, 261-266. [CrossRef]

37. Zhang, F.Q.; Wang, Y.S.; Lou, Z.P.; Dong, J.D. Effect of heavy metal stress on antioxidative enzymes and lipid peroxidation in leaves and roots of two mangrove plant seedlings (Kandelia candel and Bruguiera gymnorrhiza). Chemosphere 2007, 67, 44-50. [CrossRef] [PubMed]

38. Chérif, M.; Tirilly, Y.; Bélanger, R.R. Effect of oxygen concentration on plant growth, lipid peroxidation, and receptivity of tomato roots to Pythium F under hydroponic conditions. Eur. J. Plant Pathol. 1997, 103, 255-264. [CrossRef]

39. Velikova, V.; Yordanov, I.; Edreva, A. Oxidative stress and some antioxidant systems in acid rain-treated bean plants: Protective role of exogenous polyamines. Plant Sci. 2000, 151, 59-66. [CrossRef]

40. Mostofa, M.G.; Hossain, M.A.; Fujita, M.; Tran, L.S.P. Physiological and biochemical mechanisms associated with trehaloseinduced copper-stress tolerance in rice. Sci. Rep. 2015, 5, 11433. [CrossRef]

41. Halliwell, B.; Gutteridge, J.M. Oxygen toxicity, oxygen radicals, transition metals and disease. Biochem. J. 1984, 219 , 1-14. [CrossRef] [PubMed]

42. Nkomo, M.; Gokul, A.; Keyster, M.; Klein, A. Exogenous p-coumaric acid improves Salvia hispanica L. seedling shoot growth. Plants 2019, 8, 546. [CrossRef]

43. Asada, K. Chloroplast: Formation of active oxygen and its scavenging. Methods Enzymol. 1984, 105, 422-429.

44. Stewart, R.R.; Bewley, J.D. Lipid peroxidation associated with accelerated aging of soybean axes. Plant Physiol. 1980, 65, 245-248. [CrossRef] [PubMed]

45. Chakravarty, T.N.; Sopory, S.K. Blue light stimulation of cell proliferation and glyoxalase I activity in callus cultures of Amaranthus paniculatus. Plant Sci. 1998, 132, 63-69. [CrossRef]

46. Gronwald, J.W.; Plaisance, K.L. Isolation and characterization of glutathiones-transferase isozymes from sorghum. Plant Physiol. 1998, 117, 877-892. [CrossRef] [PubMed]

47. Vachirapatama, N.; Jirakiattikul, Y. Effect of vanadium on growth of Chinese green mustard (Brassica campestris ssp. chinensis var. parachinensis) under substrate culture. Songklanakarin J. Sci. Technol. 2008, 30, 427-431.

48. Wu, Z.Z.; Zhang, Y.X.; Yang, J.Y.; Zhou, Y.; Wang, C.Q. Effect of vanadium on testa, seed germination, and subsequent seedling growth of alfalfa (Medicago sativa L.). J. Plant Growth Regul. 2020, 1-13. [CrossRef]

49. Tham, L.X.; Nagasawa, N.; Matsuhashi, S.; Ishioka, N.S.; Ito, T.; Kume, T. Effect of radiation-degraded chitosan on plants stressed with vanadium. Radiat. Phys. Chem. 2001, 61, 171-175. [CrossRef]

50. Yan, F.; Liu, Y.; Sheng, H.; Wang, Y.; Kang, H.; Zeng, J. Salicylic acid and nitric oxide increase photosynthesis and antioxidant defense in wheat under UV-B stress. Biol. Plant. 2016, 60, 686-694. [CrossRef]

51. Gielen, B.; Vandermeiren, K.; Horemans, N.; D’haese, D.; Serneels, R.; Valcke, R. Chlorophyll a fluorescence imaging of ozone-stressed Brassica napus L. plants differing in glucosinolate concentrations. Plant Biol. 2006, 8, 698-705. [CrossRef]

52. Imtiaz, M.; Ashraf, M.; Rizwan, M.S.; Nawaz, M.A.; Rizwan, M.; Mehmood, S.; Yousaf, B.; Yuan, Y.; Ditta, A.; Mumtaz, M.A.; et al. Vanadium toxicity in chickpea (Cicer arietinum L.) grown in red soil: Effects on cell death, ROS and antioxidative systems. Ecotoxicol. Environ. Saf. 2018, 158, 139-144. [CrossRef]

53. Hassan, M.J.; Shao, G.; Zhang, G. Influence of cadmium toxicity on growth and antioxidant enzyme activity in rice cultivars with different grain cadmium accumulation. J. Plant Nutr. 2005, 28, 1259-1270. [CrossRef]

54. Aravind, P.; Prasad, M.N.V.; Malec, P.; Waloszek, A.; Strzałka, K. Zinc protects Ceratophyllum demersum L. (free-floating hydrophyte) against reactive oxygen species induced by cadmium. J. Trace Elem. Med. Biol. 2009, 23, 50-60. [CrossRef] [PubMed]

55. Nahar, K.; Hasanuzzaman, M.; Alam, M.M.; Rahman, A.; Suzuki, T.; Fujita, M. Polyamine and nitric oxide crosstalk: Antagonistic effects on cadmium toxicity in mung bean plants through upregulating the metal detoxification, antioxidant defense and methylglyoxal detoxification systems. Ecotoxicol. Environ. Saf. 2016, 126, 245-255. [CrossRef] [PubMed]

56. Bailly, C.; Benamar, A.; Corbineau, F.; Côme, D. Free radical scavenging as affected by accelerated ageing and subsequent priming in sunflower seeds. Physiol. Plant. 1998, 104, 646-652. [CrossRef]

57. Kaur, G.; Singh, H.P.; Batish, D.R.; Mahajan, P.; Kohli, R.K.; Rishi, V. Exogenous nitric oxide (NO) interferes with lead (Pb)-induced toxicity by detoxifying reactive oxygen species in hydroponically grown wheat (Triticum aestivum) roots. PLoS ONE 2015, 10, e0138713. [CrossRef]

58. Ali, M.A.; Fahad, S.; Haider, I.; Ahmed, N.; Ahmad, S.; Hussain, S.; Arshad, M. Oxidative stress and antioxidant defense in plants exposed to metal/metalloid toxicity. In Reactive Oxygen, Nitrogen and Sulfur Species in Plants: Production, Metabolism, Signaling and Defense Mechanisms; Hasanuzzaman, M., Fotopoulos, V., Nahar, K., Fujita, M., Eds.; John Wiley and Sons: Hoboken, NJ, USA, 2019; pp. 353-370.

59. Hara, M.; Yatsuzuka, Y.; Tabata, K.; Kuboi, T. Exogenously applied isothiocyanates enhance glutathione S-transferase expression in Arabidopsis but act as herbicides at higher concentrations. J. Plant Physiol. 2010, 167, 643-649. [CrossRef] [PubMed]

60. Øverby, A.; Stokland, R.A.; Åsberg, S.E.; Sporsheim, B.; Bones, A.M. Allyl isothiocyanate depletes glutathione and upregulates expression of glutathione S-transferases in Arabidopsis thaliana. Front. Plant Sci. 2015, 6, 277. [CrossRef] [PubMed]

61. Altaf, M.M.; Diao, X.P.; ur Rehman, A.; Imtiaz, M.; Shakoor, A.; Altaf, M.A.; Younis, H.; Fu, P.; Ghani, M.U. Effect of vanadium on growth, photosynthesis, reactive oxygen species, antioxidant enzymes, and cell death of rice. J. Soil Sci. Plant Nutr. 2020, 20, 2643-2656. [CrossRef] 
62. Shah, K.; Kumar, R.G.; Verma, S.; Dubey, R.S. Effect of cadmium on lipid peroxidation, superoxide anion generation and activities of antioxidant enzymes in growing rice seedlings. Plant Sci. 2001, 161, 1135-1144. [CrossRef]

63. Hasanuzzaman, M.; Nahar, K.; Anee, T.I.; Fujita, M. Exogenous silicon attenuates cadmium-induced oxidative stress in Brassica napus L. by modulating AsA-GSH pathway and glyoxalase system. Front. Plant Sci. 2017, 8, 1061. [CrossRef]

64. Lin, C.Y.; Trinh, N.N.; Lin, C.W.; Huang, H.J. Transcriptome analysis of phytohormone, transporters and signaling pathways in response to vanadium stress in rice roots. Plant Physiol. Biochem. 2013, 66, 98-104. [CrossRef] [PubMed]

65. Keyster, M.; Klein, A.; Du Plessis, M.; Jacobs, A.; Kappo, A.; Kocsy, G.; Galiba, G.; Ludidi, N. Capacity to control oxidative stress-induced caspase-like activity determines the level of tolerance to salt stress in two contrasting maize genotypes. Acta Physiologiae Plantarum 2013, 35, 31-40. [CrossRef]

66. Liu, N.; Cao, C.; Sun, Z.; Lin, Z.; Deng, R. Pollutant-induced cell death and reactive oxygen species accumulation in the aerial roots of Chinese banyan (Ficus microcarpa). Sci. Rep. 2016, 6, 36276. [CrossRef] [PubMed]

67. Mergemann, H.; Sauter, M. Ethylene induces epidermal cell death at the site of adventitious root emergence in rice. Plant Physiol. 2000, 124, 609-614. [CrossRef]

68. Hall, J.Á. Cellular mechanisms for heavy metal detoxification and tolerance. J. Exp. Bot. 2002, 53, 1-11. [CrossRef] [PubMed]

69. Viehweger, K. How plants cope with heavy metals. Bot. Stud. 2014, 55, 35. [CrossRef] [PubMed] 